\title{
Perinatal Death: Worse Obstetric and Neonatal Outcome in a Subsequent Pregnancy
}

\author{
ME Crowther \\ $M D, M^{2} C^{*}$ \\ Civilian Consultant Obstetrician and Gynaecologist
}

British Military Hospital, Rinteln, BFPO 31

SUMMARY: A retrospective case-control study was undertaken of women with a history of a previous stillbirth o neonatal death, who subsequently delivered in BMH Rinteln. Their obstetric and neonatal outcome was compare⿻ to that of a control group of women of similar age and parity and its relationship to specific socio-economic factors assessed.

Index patients had a worse obstetric and neonatal outcome. They were statistically significantly more likely to bet admitted to hospital during their pregnancy (46\% vs $26 \%$ ), to have medical complications (58\% vs $34 \%$ ), to be delivered prematurely ( $16 \%$ vs $8 \%$ ), and by Caesarean section $(22 \%$ vs $9 \%$ ). Their babies were more likely to have complications $(28.8 \%$ vs $20.4 \%)$, to be of low birth weight $(14 \%$ vs $7 \%)$, require intubation $(11 \%$ vs $5 \%)$ and he admitted to the Special Care Baby Unit (SCBU) (13\% vs 7\%).

Apart from small stature, no differences in socio-economic factors between the two groups could be identified Index patients were four times more likely than controls to have their pregnancy terminated prematurely as $\$$ result of complications $(6.7 \%$ vs $1.6 \%)$, but there was also a high level of obstetric intervention in the absence clear medical indications. Although perinatal mortality was not statistically increased, the results were suspicious and it is concluded that these women should continue to be considered a high-risk group.

\section{Introduction:}

Three large studies in the past have shown that perinatal mortality in a subsequent pregnancy is increased following a premature delivery, stillbirth or neonatal death $(1,2,3)$. Other surviving offspring have also been found to be at increased risk of neurological damage (2), significant handicap or infant death from infectious diseases, drowning or even car accidents (3), a result attributed to adverse socio-economic conditions, and poor quality of child care.

The risks to a subsequent pregnancy would seem selfevident: first, medical complications such as diabetes or hypertension may be repetitive risks and some lethal congenital abnormalities may recur (3). Second, socioeconomic factors such as social class, race, illegitimacy, poor nutrition, smoking and small stature are important correlates of fetal outcome $(4,5,6)$, and many are unlikely to change from one pregnancy to the next.

These studies were undertaken before the introduction of sophisticated fetal monitoring and a greater willingness by obstetricians to prematurely terminate an at-risk pregnancy. No further population-based studies have been done, although more recently it was found that a history of a previous stillbirth was not a risk factor per se for a poor outcome in a subsequent pregnancy, unless the mother was diabetic, hypertensive or demonstrated intrauterine growth retardation (IUGR) (7), in which case there was greater neonatal morbidity. However, the comparison group consisted of other high-risk pregnancies and not normal controls.
The current study, therefore, was undertake to quantify the risk of pregnancy to women with a pas history of a perinatal death, in the light of current obstginc practice, and to identify any socio-economic factoos which might be influential.

Subjects and Methods:

The Labour Ward delivery books and case notes of $\stackrel{\AA}{m}$ patients $(11,923)$ who had delivered in BMH Rinteln fro $\overrightarrow{0}$ January 1980 to December 1989 were searched and 28 Caucasian women were identified who had experience one or more stillbirths or neonatal deaths between $196 \%$ 88 ; the notes on 5 other women could not be found an they were therefore excluded. If women had had mo than one delivery in the hospital, only the first wo analysed.

Two controls for each index case were selected fro the delivery book retrospectively by taking the mothers same age and parity who delivered immediately before and after each index case. Twenty-three index patients parity 4-6 had to be matched with control cases of paris 3 ; two non-Caucasian cases were excluded, and a total of 572 controls were used.

Clinical data on the current pregnancy were obtain from the obstetric and paediatric case notes, if the infant had been admitted to SCBU. The age of (first) marriage was recorded in most notes, but if not, was estimated occurring one year before the first birth. In a smad

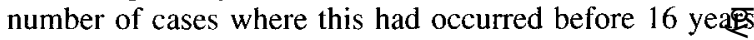
of age, "16" was used at the age of marriage. 
To approximate the Registrar General's classification of social class in Britain (8), the women were divided into two groups - wives of non-commissioned men (having manual trades compatible with social classes III and IV), and wives of Officers, Warrant Officers and civilians (having non-manual occupations consistent with social classes I and II). This is not entirely satisfactory as there are many non-commissioned men in senior positions who are highly skilled, but the number of men in such posts in both groups of the study were small.

"Perinatal death" as used in this paper was modified to include all stillbirths after 24 weeks (as resuscitation was undertaken at this stage) and all neonatal deaths within the first 8 weeks of life, to allow for premature babies or those with lethal abnormalities who had been kept alive beyond 4 weeks. It does not include babies dying from the Sudden Infant Death Syndrome at any stage, or from infection or other treatable diseases after 4 weeks of life.

Results are presented as differences in mean values and proportions, and analysed using the Confidence Interval Analysis program (9).

\section{Results:}

The current pregnancy followed the perinatal death in 162 cases $(57 \%)$, and $30 \%$ of the women had had only that one previous fatal pregnancy. Eighteen women $(6.3 \%)$ had a history of two perinatal deaths in the past.

of the eight variables considered, only small stature was significantly more common in index cases (Table 1). Sixteen percent of the index patients had had a previous Caesarean section $(\mathrm{C} / \mathrm{S})$, and in $73 \%$ of these cases the baby had been delivered stillborn (13 cases), or died subsequently (Table 2).

Index patients had a significantly higher overall incidence of complications but, because of small numbers, when assessed individually no statistical differences between the two groups were found for bleeding in early pregnancy, raised blood pressure, diabetes, premature labour, IUGR, antepartum haemorrhage, multiple pregnancy, malpresentation and assorted other medical problems.

Nevertheless, index patients cumulatively had a higher incidence of serious complications ( $22.9 \%$ vs $14 \%$ ), they were more likely to be admitted to hospital and their stay was longer. Of these, 19 index patients $(29.2 \%)$ and 9 controls $(11.2 \%)$ were delivered prematurely or as an emergency, a difference which was also significant $(95 \%$ CI 4.9 to 31.0 ).

Similar proportions of women in both groups were induced. In half the cases $(63 / 127,49.6 \%$ vs $141 / 243$, $58 \%$ controls) this was for a significant medical complication such as hypertension, diabetes, IUGR, antepartum haemorrhage, abnormal fetal heart rate or antibodies. The remaining $42 \%$ of control patients were induced for "logistic reasons" (term gestation, maternal request because of husband's military commitments, cervix favourable). Of the remaining index patients, $23 \%$ were induced "logistically" and the other $27 \%$ because of their "past obstetric history", in the absence of any other 8 medical complication (Table 3).

Statistically significantly more index cases were 0 of delivered prematurely, and by $\mathrm{C} / \mathrm{S}$. Half of all the premature deliveries of index patients (22/44) resulted

Table 1

\section{Socio-Economic Characteristics of Subjects and Controls}

(Values are means (SDs) or numbers (\%) unless otherwise stated)

\begin{tabular}{|c|c|c|c|c|}
\hline & $\begin{array}{l}\text { Subjec } \\
(n=28\end{array}$ & & $\begin{array}{l}\text { Controls } \\
(n=572)\end{array}$ & $\begin{array}{l}95 \% \text { confidence intervals } \\
\text { for differences in means } \\
\text { or percentages } \\
\text { (* = statistical significance) }\end{array}$ \\
\hline $\begin{array}{l}\text { Current age } \\
\text { (yrs) (range) }\end{array}$ & $\begin{array}{r}26.2 \\
(17\end{array}$ & $\begin{array}{l}(4.3) \\
-39)\end{array}$ & $\begin{array}{c}26 \quad(4.0) \\
(18-39)\end{array}$ & - \\
\hline $\begin{array}{l}\text { Age 1st. } \\
\text { marriage (yrs) }\end{array}$ & 20.2 & $(2.9)$ & $19.9 \quad(2.7)$ & -0.09 to 0.69 \\
\hline Re-married & 30 & $(10.6 \%)$ & $(8.9 \%)$ & -2.6 to 5.9 \\
\hline Non-commission status & 258 & $(90.8 \%)$ & $510 \quad(89.2 \%)$ & -2.5 to 5.9 \\
\hline Smokers & 148 & $(52.1 \%)$ & $261 \quad(45.6 \%)$ & -0.6 to 13.6 \\
\hline $\mathrm{Ht}(\mathrm{cm})$. & 161 & $(7.7)$ & $(6.8)$ & -2.0 to 0.02 \\
\hline Ht. $<150 \mathrm{~cm}$. & 21 & $(7.4 \%)$ & $21 \quad(3.7 \%)$ & 0.3 to $7.1^{*}$ \\
\hline $\begin{array}{l}\mathrm{Wt}(\mathrm{Kg}) \text { at } \\
\text { onset of preg. }\end{array}$ & 62.8 & (12.1) & $63.4(12.6)$ & -2.4 to 1.2 \\
\hline Wt. $<50 \mathrm{Kg}$. at onset & 36 & $(12.7 \%)$ & $68 \quad(11.9 \%)$ & -3.9 to 5.5 \\
\hline
\end{tabular}

$95 \%$ confidence intervals

for differences in means or percentages

(* = statistical significance) 
Table 2

Characteristics of the Current Pregnancy

(Values are means (SDs) or numbers (\%) unless otherwise stated)

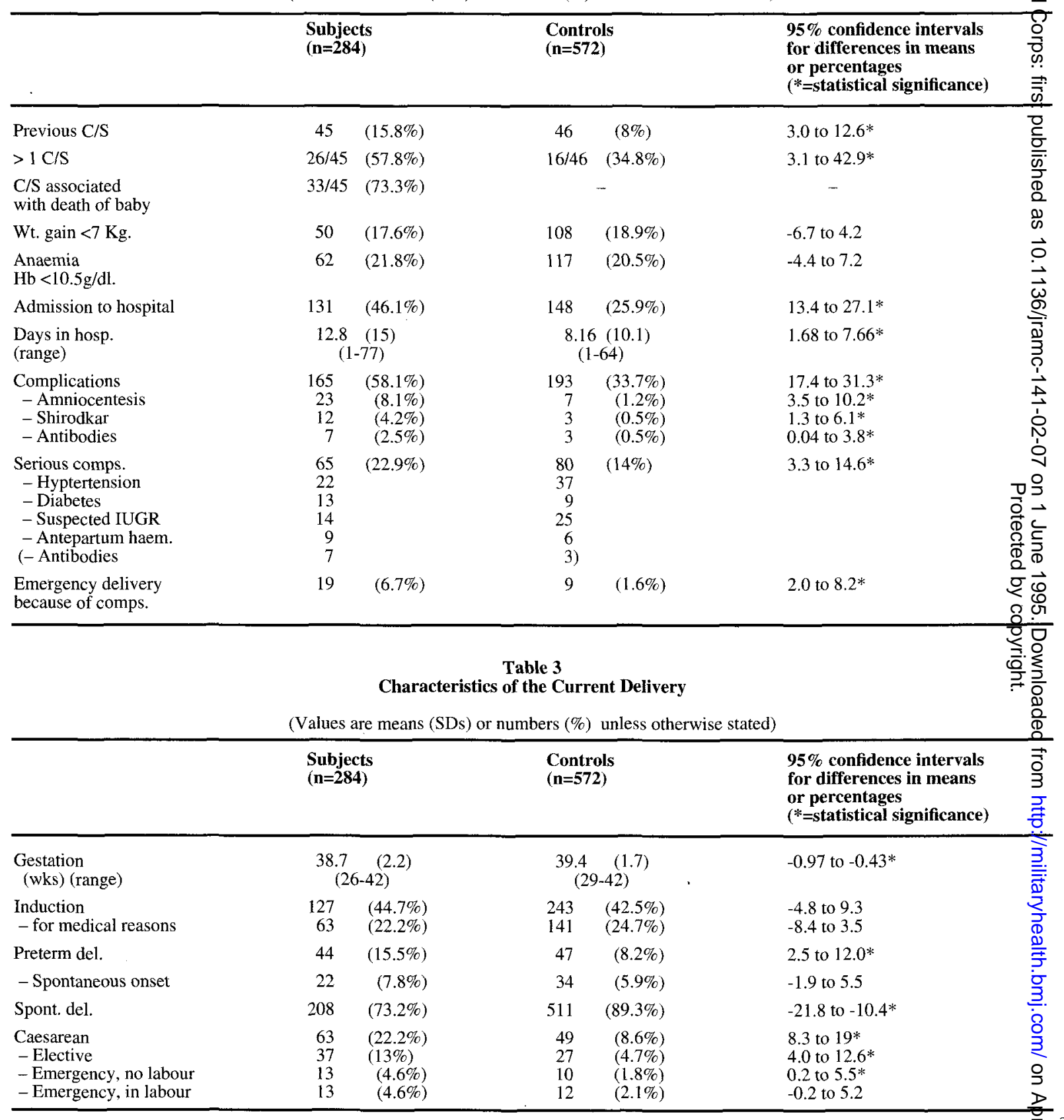

from obstetric intervention for complications, compared with $28 \%$ (13/47) in the control patients (95\% CI 2.8 to 41.9).

Babies in the index group were significantly more likely to be jaundiced ( $21 \%$ vs $15 \%$; $95 \%$ CI 0.28 to 11.4 ) and cumulatively experienced more complications in the neonatal period. However, when assessed individuaffy there were no differences between the groups with respeot to the following: severe sepsis, respiratory distrens syndrome, hypoglycaemia, meconium aspiration, exchange transfusion, phototherapy, chromosomal \&r other abnormalities. 
Table 4

Characteristics of Neonatal Outcome

(Values are means (SDs) or numbers (\%) unless otherwise stated)

\begin{tabular}{|c|c|c|c|c|c|}
\hline & \multicolumn{2}{|c|}{$\begin{array}{l}\text { Subjects } \\
(\mathbf{n}=\mathbf{2 8 7})\end{array}$} & \multicolumn{2}{|c|}{$\begin{array}{l}\text { Controls } \\
(n=578)\end{array}$} & \multirow{2}{*}{$\begin{array}{l}95 \% \text { confidence intervals } \\
\text { for differences in means } \\
\text { or percentages } \\
\text { (*=statistically significance) }\end{array}$} \\
\hline $\begin{array}{l}\text { Birth weight } \\
\text { (gm.) (range) }\end{array}$ & \multicolumn{2}{|c|}{$\begin{array}{c}3131 \quad(627) \\
(740-4800)\end{array}$} & \multicolumn{2}{|c|}{$\begin{array}{c}3308 \quad(560) \\
(800-4700)\end{array}$} & \\
\hline Babies <2.5 Kg. & 39 & $(13.6 \%)$ & 42 & $(7.3 \%)$ & 1.8 to $10.8^{*}$ \\
\hline Perinatal death & 6 & $(2.1 \%)$ & 5 & $(0.8 \%)$ & -0.59 to 3.0 \\
\hline o Apgar $<7$ & 56 & $(19.6 \%)$ & 82 & $(14.2 \%)$ & -0.04 to 10.8 \\
\hline o Intubated & 30 & $(10.5 \%)$ & 30 & $(5.2 \%)$ & 1.3 to $9.3^{*}$ \\
\hline o Complications & 81 & $(28.8 \%)$ & 117 & $(20.4 \%)$ & 2.2 to $14.6^{*}$ \\
\hline $\begin{array}{l}\text { Admitted to } \\
\text { SCBU }\end{array}$ & 37 & $(12.9 \%)$ & 38 & $(6.6 \%)$ & 1.9 to $10.7^{*}$ \\
\hline $\begin{array}{l}\text { Days in SCBU } \\
\text { (range) }\end{array}$ & $\begin{array}{r}14.4 \\
(2-72)\end{array}$ & $(13.7)$ & 14.6 & $\begin{array}{l}(16.7) \\
(2-68)\end{array}$ & -7.3 to 6.8 \\
\hline
\end{tabular}

o excludes stillbirths

The six perinatal deaths in the index group resulted from prematurity ( 26 and 27 weeks), IUGR at 36 weeks (weight 760g.), and congenital abnormalities (Roberts' Syndrome and Potter's Syndrome, in 2 women whose previous children had died similarly; and a third child with dysmorphic features). The five perinatal deaths in the control group were from prematurity (33 weeks), IUGR at 29 weeks (weight $800 \mathrm{~g}$.) and intrapartum asphyxia in 3 term babies (cord tightly around the neck; severe bradycardia during delivery of a baby with an unsuspected large spina bifida; and bradycardia at $8 \mathrm{~cm}$. dilatation, with ventouse delivery of a stillborn infant and postmortem evidence of an intracranial haemorrhage and liver haematoma) (Table 4).

\section{Discussion}

The increased neonatal morbidity following a previous premature delivery, stillbirth or neonatal death $(1,2,3)$ has been partly attributed to socio-economic disadvantage (3). Although social class influences peri- and neo-natal mortality in the general population $(6,11)$, its role in the Army is not clear. This is a unique environment in which obvious material socio-economic differences between people are kept to a minimum with the provision of adequate housing, employment, welfare services and comprehensive health care. That this rather than "social class" can have a positive influence has been shown by the lower perinatal mortality rates of black babies in the American military compared to the general population (12).

Other risk factors for a perinatal death $(4,5,6)$ or premature labour (13) such as smoking and poor nutrition (crudely reflected by anaemia, low body weight and height, and poor weight gain during pregnancy) were not significantly different in both groups. Non-Caucasian race and illegitimacy did not apply to the women in this study, and insofar as young age and domestic instability are associated with an adverse obstetric outcome (1), the average age of marriage in both groups was the same (young), and there were similar proportions of women who had remarried.

Thus, even if socio-economic factors may have played a role in the original perinatal death, they now had a negligible influence on the worse outcome of the index group. The predominant difference was the higher incidence of medical complications, and the obstetric response to them. Some of these, such as the need for amniocentesis or a Shirodkar suture, could be attributed to the circumstances of the original perinatal death ( 20 of the amniocenteses were performed because of a previous neural tube defect, compared with only one among the controls). However, index patients were four times more likely than controls to experience an emergency $\mathrm{C} / \mathrm{S}$ or termination of the pregnancy prematurely because of serious complications $(6.7 \%$ vs $1.6 \%)$. Even amongst all patients with complications, they were still more than twice as likely as the controls to experience intervention $(19 / 65,29.2 \%$ vs $9 / 80,11.2 \%)$.

The high induction rate in all patients resulted from an Army policy aimed at preventing delivery in a German civilian hospital. Induction for "past obstetric history" reflected the tradition of delivering women at 38 weeks if they had previously suffered an abruption or intrauterine death, often in the absence of any other factor. The proportion of patients induced in both groups for genuine medical complications was the same, however, confirming that when index patients had a serious complication, it tended to occur before 38 weeks and be managed other than by induction. 
There was a high incidence of elective $\mathrm{C} / \mathrm{S}$ in the index patients and in nearly three-quarters of cases (27/37), this decision was influenced by maternal anxiety, the previous history, or previous surgical complications. Fourteen sections were performed because of the previous death, or at the mother's request, in the absence of any other obstetric indication (all 14 deaths were intrauterine of unknown aetiology, or stillbirths after an abruption). This suggests that both women and their obstetricians consider that the safest way to deliver a baby is abdominally, and the effect of maternal anxiety in influencing obstetric decisions cannot be underestimated. In two further cases maternal insistence that the baby was not moving led to premature abdominal delivery at 37 weeks, in spite of ultrasonic and cardiotocographic evidence of healthy and normally moving babies. A further 5 sections were required because of complications arising from the original emergency $\mathrm{C} / \mathrm{S}$ performed under extreme circumstances at the time of the perinatal death. In two of these cases a "classical" incision had been made; a third woman had suffered a ruptured uterus in a later pregnancy and another stillborn; and two other women had required repeat sections subsequently because of painful scars, which at operation were found to be thin. Finally, 6 sections were performed in women who had previously had a section for no apparent reason other than the prior perinatal death.

The reasons for the emergency sections were similar in both groups (medical complications antenatally, abnormal labour or fetal distress), although 9 of the index patients of low stature $(43 \%)$ had a $\mathrm{C} / \mathrm{S}$, compared with only one of the controls $(5 \%)$, suggesting that where there has been a previous perinatal death, the obstetric threshold for intervention in a labour which is not progressing normally, or the willingness to attempt a trial of labour, is very low.

The worse neonatal outcome relates to the higher incidence of premature delivery in the index patients, which in $50 \%$ of cases resulted from an obstetric decision to terminate the pregnancy. Otherwise similar proportions of women in both groups went into spontaneous premature labour and delivered. Although the perinatal mortality rate was not significantly increased for the index patients, the numbers were small, and a rate of $2.1 \%$ (21 per 1000) is still higher than the rate for England and Wales, which between 1980-84 fell from 13.3 to 10.1 per 1000 births. The corresponding rates for Army births in West Germany, which had always been lower than those for England and Wales (14) fell from 13.1 to 5.5. per 1000 , a rate similar to that of the control group in the study ( 8 per 1000$)$. It should also be remembered that $6 \%$ of the index patients had had two previous perinatal deaths before entering the study, and that the figures for both groups are an underestimate because they do not take into account the number of pregnancies which were electively terminated once congenital abnormalities were detected antenatally (small), or which might have aborted spontaneously (unknown). The two perinatal deaths from Potter's and Roberts' Syndrome in women who had previously hadoे similar children, and one among the controls (the baby with spina bifida), were potentially avoidable hado appropriate ultrasonic scanning been undertaken.

What is not clear from this study is whether medical complications were genuinely more serious in these? women or whether obstetricians reacted to them more? aggressively in the light of the previous history, although을 the results would tend to support the latter. It was clear, $\bar{D}$ for example, that the prolonged admission to hospital of $\stackrel{\mathbb{Q}}{\varrho}$ many index patients often resulted not so much from the severity of the medical complication but maternal anxiety $\overrightarrow{ }$ and a feeling of security when being monitored in. hospital. It is also not possible to infer to what degree the $\vec{\omega}$

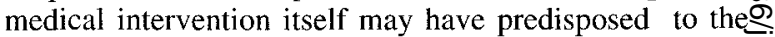
worse outcome, because a retrospective study cannot take@ into account all the factors which influenced a particular? medical decision at that time. Finally, although the study $\vec{A}$ was unable to confirm statistically that these women have $\rightarrow$ a higher perinatal mortality rate, because of the smallo numbers involved, the results are suspicious, but only ac large population-based study would be able to adequatelyo quantify this.

\section{REFERENCES}

1. Butler NR, Bonham DG, eds. Perinatal Mortalif the first report of the British Perinatal Mortality St vey. Edinburgh: E \& S Livingston Ltd., 1963.

2. Niswander KR, Gordon M, eds. Collaborat Perinatal Study of the National Institute of Neurolog Disease and Stroke: the women and their pregnancies. DHEW Publication No. (NIH) 73-379, Washington DC, 1972.

3. NEwCOMBE HB. Risks to siblings of stillborn children. Can Med Assoc J 1968; 98: 189-93.

4. Evans CM. Risk and the Neonate. In: JaMES DK, STIRRAT GM (Eds). Pregnancy and Risk: the basis for rational management. London: John Wiley \& Sons Ltd, 1988.

5. Clarke M, Clayton DG, Mason es Macvicar J Asian mothers' risk factors for perinatal death - the same or different? A 10 year review of Leicestershire perinatal deaths. Br Med $J$ 1988; 297:384-7.

6. LeON DA, VAGERö D, Olausson PO. Social class differences in infant mortality in Sweden: comparison with England and Wales. Br Med J 1992; 305:687-을 91.

7. Freeman RK, Dorchester W, Anderson G, Garite TJ. The significance of a previous stillbirth. $A m$. Obstet Gynecol 1985; 151:7-13.

8. Office of Population Censuses and Surveys Classica- N tion of Occupations. London: HMSO, 1980.

9. Gardner MJ, Gardner SB, Winter PD. Confidenceñ Interval Analysis (CIA). Microcomputer Program Manual, Version 1.1. Br Med J London, 1989. 
10. Fedrick J, Anderson ABM. Factors associated with spontaneous pre-term birth. Br J Obstet Gynaecol 1976; 83:342-50.

11. Chalmers I. Short, Black, Baird, Himsworth and social class differences in fetal and neonatal mortality rates. (Editorial). $\mathrm{Br}$ Med $J$ 1985; 291:231-2.

12.RAWLINGS JS, WEIR MR. Race- and rank-specific infant mortality in a US military population. Am J Dis
Child 1992; 146:313-6.

13. CROWTHER ME. A retrospective study of all low birthweight preterm babies born in BMH Rinteln between 1980-1989. J R Army Med Corps 1990; 136:43-9.

14. Atalla A, Page I, OAK M. Review of perinatal mortality in BAOR 1970-1984. J R Army Med Corps 1986; 132:173-6.

\section{RAMC CENTENARY COMMEMORATIVE PUBLICATION}

Production of a History of the Royal Army Medical Corps to commemorate the Centenary Year in 1998 is already well in hand.

To complement this historical publication it is also planned to publish a "Coffee Table" pictorial supplement, probably by way of introduction to the main publication.

It is hoped to include in this pictorial supplement previously unpublished photographs, or little known facts about the Corps, that will be of interest to readers of the finished work.

Readers of this Magazine are therefore invited to submit photographs, cartoons, diagrams, or any other items of historical interest for consideration by the working party, for inclusion in this book.

Items should be addressed to:

Staff Assistant, Royal Army Medical College,

Millbank, London SW1P 4RJ 